\title{
management revue, published and forthcoming
}

\section{Manfred Moldaschl (ed.): Beyond Resource Based View}

management revue, special issue, ISSN 0935-9915, vol 15, issue 1

Rainer Hampp Verlag, Muenchen u. Mering 2004, 166 S., $€ 14.80$

Rüdiger Kabst, Wolfgang Weber (eds.): Theoretical Perspectives for Human Resource Management: The German Discussion management revue, special issue, ISSN 0935-9915, vol 15, issue 2, Rainer Hampp Verlag, Muenchen u. Mering 2004, 106 S., € 14.80

Jan Kees Looise, Maarten van Riemsdijk (eds.):

\section{Organisational Innovation and HRM}

management revue, special issue, ISSN 0935-9915, vol 15, issue 3, Rainer Hampp Verlag, Muenchen u. Mering 2004, 132 S., € 14.80

Albert Martin (ed.): New Directions in Organizational Behaviour management revue, special issue, ISSN 0935-9915, vol 15, issue 4,

ISBN 3-87988-883-3, Rainer Hampp Verlag, Muenchen u. Mering 2004, 132 S., € 14.80

Mark Fenton O'Creevy, Paul Gooderham, Odd Nordhaug (eds.):

Diffusion of HRM to Europe and the Role of US MNCs management revue, special issue, ISSN 0935-9915, vol 16, issue 1, ISBN 3-87988-906-6, Rainer Hampp Verlag, München und Mering 2005, 155 S., € 19,80

Rüdiger Kabst, Wenzel Matiaske (eds.):

Human Resource Management and Economic Success

management revue, special issue, ISSN 0935-9915, vol 16, issue 2,

ISBN 3-87988-906-6, Rainer Hampp Verlag, München und Mering 2005, 138 S., € 19,80

\section{Forthcoming}

Industrial Relations in Europe

Flexible Work = Atypical Work = Precarious Work?

Management of Interorganizational Relationships 